\title{
NEW MODEL OF CEMENT PRODUCT - PRECAST SLAB TRACK FOR THSR (TAIWAN HIGH SPEED RAIL)
}

\author{
Yan-Chyuan Shiau \\ Associate Professor \\ Dept. of Const. Engr., Chung Hua University \\ 707, Sec.2, WuFu Rd., HsinChu, Taiwan \\ ycshiau@ms22.hinet.net \\ Ming-Teh Wang \\ President of Taiwan Const. Research Institute \\ 11Fl., No.190, Sec.2, Chung-Hsing Road, Hsintien, \\ Taipei, Taiwan \\ mtwang@tcri.org.tw
}

\author{
Chih-Ming Huang \\ Graduate Student \\ Institute of Const. Magr, Chung Hua University \\ 707, Sec.2, WuFu Rd., HsinChu, Taiwan \\ jimmy_huang@ispeed.com.tw

\section{Lian-Ting Lu} \\ General Affairs Division, Construction \& Mainte- \\ nance Section \\ Nan-Hua University, Jia-Yi, Taiwan \\ ltleu@mail.nhu.edu.tw
}

\begin{abstract}
The development of "slab track" was started by Japan in 1955 and the "Committee of slab track research" was established in 1971 for exclusive development of slab track. This makes Japan the country that has invested the most effort into slab tracks. On $5^{\text {th }}$ January 2007, the THSR transferred from Japanese Shinkansen started its commercial operation. The stability and comfort of train operation have received a good reputation from the general public. The research results of the slab track system in Shinkansen is already the masterpiece recognized worldwide and among it, the pre-cast track system is one of the most important components in the system. This article introduces and discusses the features of quality management by Japanese enterprises on production of slab tracks, which can act as a reference and application for the cement industry in Taiwan.
\end{abstract}

\section{KEYWORDS}

Slab track, Taiwan High Speed Rail, Pre-cast track system, Quality management

\section{PREFACE}

From theoretical analysis and the paving test on the test line and existing line, the slab track has been proven to provide distinctive superiority far greater than conventional ballast tracks in terms of safety and comfort during high speed travel, which is also more favoured in economic aspects than the ballast track (the maintenance cost of slab tracks is approximately $1 / 10$ of ballast tracks). At present, construction of new railways in Japan uses slab tracks except in special circumstances. The new regulation even specifies that slab tracks must be used for bridges and tunnels [1]. 
Compared to conventional ballast tracks, the slab track provides the following advantages [2]:

- Better track structure and stability

- Better track flexibility

- Better durability

- Economic and reasonable construction price

- Saving of maintenance expense

The J-slab track adopted by THSR (Figure 1) [3] mainly consists of roadbed, projection, CA-mortar, J-Slab, rail and fasteners. The slab plays a significant role in the slab track system since it directly sustains and delivers external forces of the train such as loading, centrifugal force, impact and vibration, thus the requirement of quality is extremely strict. Whether for assessment and establishment of documentation, product surface and control of precision, the managing style of Japanese enterprises has set a new model for the cement industry in Taiwan.

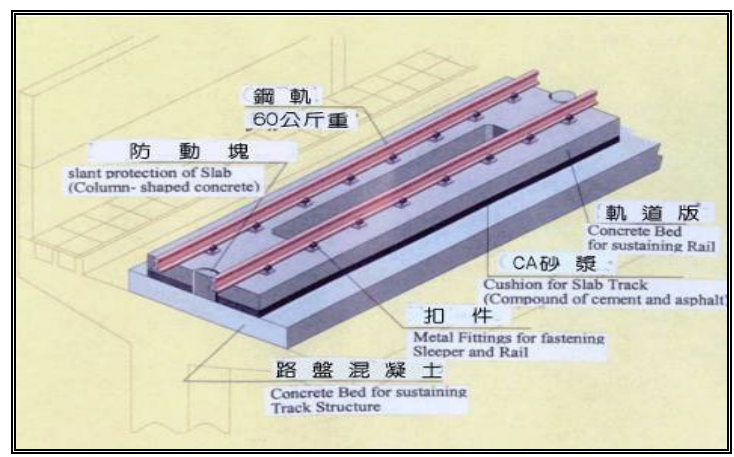

Figure 1. J-slab track

\section{INTRODUCTION OF THSR TRACK WORKS}

The length of THSR track system is approximately $345 \mathrm{~km}$ with the inclusion of:

- J-slab track: $298.977 \mathrm{~km}$ of main line (86.6\%).

- $\quad$ Rheda track: Mainly allocated at station, crossover and turnout area for $27.326 \mathrm{~km}(7.9 \%)$.

- Ballast track: Located at south end of HSR for $3.265 \mathrm{~km}(0.9 \%)$

- Low vibration track at Taipei underground section: Approximately $16 \mathrm{~km}(4.6 \%)$.
Among the above tracks, the J-slab track transferred from Japanese Shinkansen is the main track system for the main line of THSR. The track design uses the track section of JIS $60(60.8 \mathrm{~kg} / \mathrm{m})$ specification with sectional area of $7750 \mathrm{~mm}^{2}$. International standard of gauge at $1.435 \mathrm{~m}$ (the gauge for Taiwan Railway is $1.067 \mathrm{~m}$ ) is provided as the single track line for north and south bound lines, which is secured by Shinkansen's 8R Fasteners onto the slab.

The full length of THSR track work is $345 \mathrm{~km}$ and except for the Taipei underground section, the remaining work of approximately $330 \mathrm{~km}$ is contracted to TST JV (Taiwan Shinkansen Track Joint Venture), which consists of the business entity formed by the seven largest firms, namely the Mitsubishi heavy industry, Toshiba, Kawasaki heavy industry, Missui, Mitsubishi corporation, Marubenni and Sumitomo corporation from Japan. Among them, the Sumitomo Mitsui is the co-vendor of TST $\mathrm{JV}$, which is in charge of production and manufacturing of all slabs.

\section{QUALITY MANAGEMENT FOR PRECAST SLAB TRACK}

\subsection{Factory and equipment planning}

The factory includes main areas such as plant, mix plant and product storage. Smooth planning of moving path will provide concise and easy management of area distribution. The plant area is approximately $15,000 \mathrm{M}^{2}$ and the space planning mainly includes:

Reinforcement fabrication area: The main equipment includes 2 gantry cranes at $2.8 \mathrm{~T}, 2$ reinforcement cutters and 2 reinforcement benders.

Assembly and storage area for reinforcement cage: The main equipment includes 2 gantry cranes at $2.8 \mathrm{~T}$ and 6 platforms for reinforcement assembly.

Production line A, B, C (Figure 2): Each production line is independent and its equipment includes 20 sets of grinding machines, 1 gantry crane at 7.5T, 2 sets of concrete bucket at capacity of $2 \mathrm{M} 3$, one curing pool with capacity of 96 slabs, steam curing equipment (4 control wires) and product inspection area. 


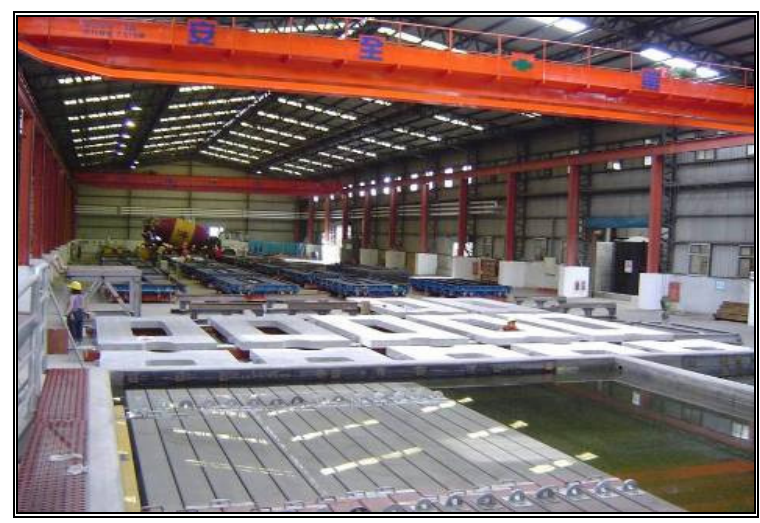

Figure 2. Production line

The mix plant is approximately $1.5 \mathrm{~km}$ from the plant or a 5 7 minutes drive. It can control concrete for completion of placing within a valid mix time (60 minutes). The main equipment includes 4 cement storage buckets at a capacity of $150 \mathrm{~T}, 4$ aggregate storage buckets, 2 conveyor belts for materials, 4 cement additive tanks and 1 set of automatic mix equipment at a capacity of $2 \mathrm{M} 3$. The storage area is located next to the plant with an area of approximately $20,000 \mathrm{M} 2$ and is capable of storing 6,000 slab tracks according to the storage program[4].

\subsection{Organizational structure of quality management}

The production of slab tracks adopts the lump-sum manner, i.e. TST JV undertakes design, supervision and construction. Prior to official production, the JV must submit the ITP (Inspection and Testing Plan) for acquiring authorization of SONO (Statement of No Objection) from THSR. The content includes construction procedures, observation point for resumption of works, sampling or testing point requiring suspension, test items, frequencies, methods and regulation of accordance, as well as development of relevant management forms. The forms shall be designed and modified by the JV. Each blank column in the forms must be filled and the columns related to the site must even be filled on site [5]. The JV is obliged to provide and keep all documents of quality records. In addition to regular audit, THSR is entitled to audit with notifying the JV and the JV cannot refuse.

THSR does not force the TST JV to obtain ISO certification; however, the contract specifies that the stan- dard of quality shall not be lower than the requirement of ISO 9001. Contractor of each track lot shall allocate a QAM (Quality Assurance Manager) who supervises execution of the project, improve and enhance the procedures of quality assurance, so the execution of the project can be ensured. The QAM reports to the GPD (General Project Director) and PD (Project Director) with subordinates of DQAM (Design Quality Assurance Manager) and CQAM (Construction Quality Assurance Manager) to assist in execution of quality assurance program of design and construction. The RE office of THSR for each lot is provided with QAM and QA engineer in charge with supervising contractors' quality assurance. The supervision is mainly carried out by means of sampling audit and the audit form is drafted by the relevant QA engineer according to type of slab track. In case of any inconsistency against the requirements during audit, the QC (Quality Control) unit of the contractor will be requested to issue a NCR (Non-Compliance Report), where the case can only be closed after listing, follow-up and qualification.

In addition, the THSR has employed the LRPT (Lloyd's Register Project Team) as external auditor according to C\&OA (Construction \& Operation Agreement) of THSR for IV\&V (Independent Verification \& Validation) to ensure the requirements of track works. The ICE (Independent Checking Engineer) and ISE (Independent Site Engineer) act as the external design assessment and construction audit units established by THSR itself. IREG will undertake the independent audit against design and construction of the track contractor, so compliance of design and construction for slab track with requirements of THSR regulation can be ensured [6].

\subsection{Material management}

In order to ensure the quality of material, inspection through the correct procedures shall be made prior to entry and storage. All materials required for manufacturing slab tracks must qualify with inspection by laboratory institutes acknowledged by CNLA. The procedures and results of inspection shall comply with requirements of THSR regulation. The storage of material is managed in areas according to its characteristics (Table 1). The total storage capacity of mix plant is $600 \mathrm{M}^{3}$ and available for 3-4 days of work. 
The materials are delivered to the storage bucket of mix equipment via conveyor belt and each cement storage bucket can store 150T of Type I cement [4].

\subsubsection{Mold assembly and inspection}

The molds (Figure 4) shall be checked immediately upon arrival. The appearance shall be checked once per month to ensure there is no condition of damage or deformation for compliance with size requirement. 模床

After completion of mold assembly, check the appearance, dimension, position and location of embeds (Figure 3).

Check precision requirement (Table 2) [7].

Table 1. Storage area and characteristics

\begin{tabular}{|c|c|c|}
\hline Material & Storing method & Storage management \\
\hline Cement & Cement storage bucket & $\begin{array}{l}\text { Prevent air pollution upon purchase of material. } \\
\text { The storage bucket shall be kept clean inside while the outside is specified } \\
\text { with type and source of cement. } \\
\text { Upon arrival and offloading of material on site, the personnel shall super- } \\
\text { vise throughout the process. }\end{array}$ \\
\hline Aggregate & $\begin{array}{l}\text { Aggregate storage } \\
\text { bucket }\end{array}$ & $\begin{array}{l}\text { The storage bucket shall be kept clean inside. } \\
\text { Entry of moisture and dust in the bucket shall be prevented. }\end{array}$ \\
\hline Additive & $\begin{array}{c}\text { Storage tank for water } \\
\text { reducing agent \& air en- } \\
\text { training agent }\end{array}$ & $\begin{array}{l}\text { Water leakage is strictly prohibited for prevention of pollution and chemi- } \\
\text { cal reaction. } \\
\text { Suitable mixer shall be provided in the tank for regular mixing. }\end{array}$ \\
\hline Reinforcement & Inspection area & $\begin{array}{l}\text { The storage area shall be kept clean and dry for prevention of surrounding } \\
\text { chloride, grease and soil that cause rust in reinforcement. } \\
\text { Slid shall be placed during reinforcement storage for prevention of direct } \\
\text { contact with ground surface. }\end{array}$ \\
\hline Square reinforcement & Material storage area & $\begin{array}{l}\text { Prevent moisture that rusts material. } \\
\text { The storage area shall be kept clean for prevention of contamination. } \\
\text { Slid shall be placed during storage for prevention of direct contact with } \\
\text { ground surface. }\end{array}$ \\
\hline Insert $\mathrm{A}, \mathrm{C}$ & Material storage area & $\begin{array}{l}\text { Slid shall be placed during storage for prevention direct contact with } \\
\text { ground surface. } \\
\text { Storage area shall be kept clean and dry for prevention of surrounding } \\
\text { chloride, grease and soil that cause rust in reinforcement. }\end{array}$ \\
\hline Screw Set & Material storage area & $\begin{array}{c}\text { Slid shall be placed during screw storage for prevention of direct contact } \\
\text { with ground surface. } \\
\text { The screws shall be stored in different packets. }\end{array}$ \\
\hline $\begin{array}{l}\text { Explosion proof rein- } \\
\text { forcement }\end{array}$ & Material storage area & $\begin{array}{l}\text { Slid shall be placed during storage for prevention of direct contact with } \\
\text { ground surface. }\end{array}$ \\
\hline Welding material & Material storage room & $\begin{array}{l}\text { Prevent moisture that rusts material. } \\
\text { Slid shall be placed during storage for prevention of direct contact with } \\
\text { the ground surface. }\end{array}$ \\
\hline
\end{tabular}




\subsection{Process management}

\subsubsection{Flow chart of process inspection [7]}

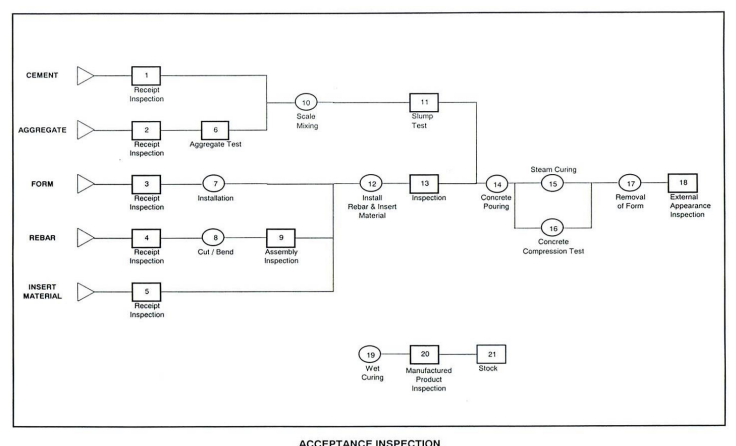

Figure 3. Process inspection flow chart [7]

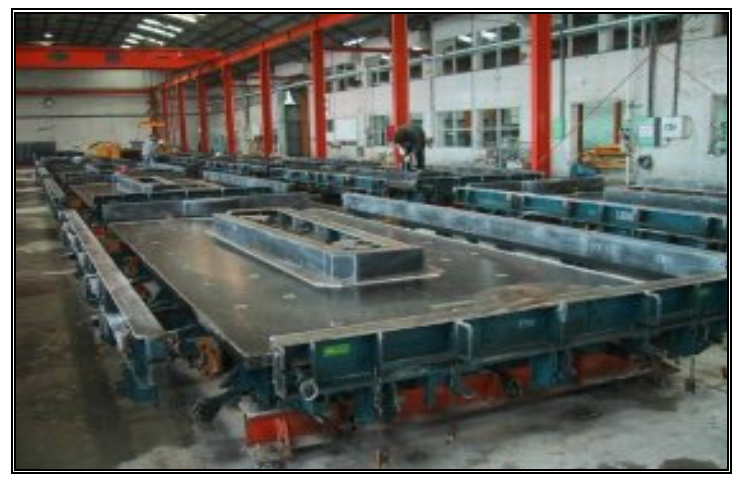

Figure 4. Molds for slab tracks

\subsubsection{Reinforcement bending and assembly}

The cutting and bending of reinforcement shall be inspected according to the construction drawing, as well as the assembly platform of reinforcement cage (Figure 5).

After fabrication, check the dimension and length of reinforcement (cutting and bending), which is followed by fastening fixture with wires according to the requirement of design drawing.

Record the check of reinforcement fabrication and assembly on the check form.

Check embeds.

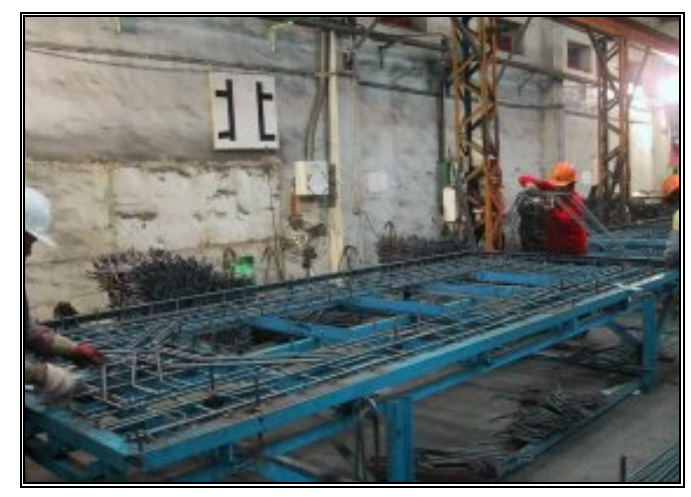

Figure 5. Assembly platform for reinforce cage

Properly fix Insert plug A, Insert Plug C and explosion proof reinforcement on the steel mold for prevention of displacement due to vibration during concrete placing.

\subsubsection{Check reinforcement placement and formwork assembly}

Check relevant positions between reinforcement placement (Figure 6) and steel mold. Please re-check in case of modification.

Fix the steel mold with clips and visually check for hammer loosening.

\subsubsection{Concrete mix and placement}

After completion of each mix, record the amount and ratio of all mixed materials, and as well check the mix time.

The allowable tolerances of materials used are as follows: Cement and water: $\pm 1 \%$; aggregate: $\pm 2 \%$; additives: $\pm 3 \%$.

The measuring equipment must be calibrated at least once every six months.

The temperature of new concrete mix must be between $13^{\circ} \mathrm{C} \sim 32^{\circ} \mathrm{C}$.

During concrete delivery and placing, contamination, aggregate separation and leakage shall be prevented. Complete the placing at 60 minutes after mixing concrete. 
Table 2. Comparison of precision requirement on mold assembly and products

\begin{tabular}{|c|c|c|c|c|c|c|}
\hline & Inspection Item & $\begin{array}{c}\text { Inspection } \\
\text { Instrument } \\
\text { Device }\end{array}$ & $\begin{array}{l}\text { Standard } \\
\text { Value } \\
(\mathrm{mm})\end{array}$ & $\begin{array}{l}\text { Formwork } \\
\text { Allowance } \\
\text { (plate m) }\end{array}$ & $\begin{array}{l}\text { Slab } \\
\text { Allowance } \\
(\mathrm{mm})\end{array}$ & Note \\
\hline Externals & $\begin{array}{l}\text { Length } \\
\text { Width } \\
\text { Thickness }\end{array}$ & $\begin{array}{l}\text { Steel Tape } \\
\text { Steel Tape } \\
\text { Scale }\end{array}$ & $\begin{array}{r}4,900 \\
2,200 \\
190\end{array}$ & $\begin{array}{l} \pm 1.5 \\
\pm 1.5 \\
+1.5\end{array}$ & $\begin{array}{l} \pm 3 \\
\pm 3 \\
+3\end{array}$ & \\
\hline Size & Corner Size & Steel Tape & Right \& Left Diff & $\begin{array}{l}\sim 0 \\
\pm 1.5\end{array}$ & $\sim 0$ & \\
\hline $\begin{array}{l}\text { Center Line } \\
\text { Interval }\end{array}$ & $\begin{array}{l}\text { Slab side and slab centerline } \\
\text { Slab center line and rail center line } \\
\text { Rail center line interval }\end{array}$ & $\begin{array}{l}\text { Scale / Gauge } \\
\text { Scale / Gauge } \\
\text { Scale / Gauge }\end{array}$ & $\begin{array}{r}1,110 \\
755 \\
1,510 \\
\end{array}$ & $\begin{array}{l} \pm 1.5 \\
\pm 0.5 \\
\pm 0.5\end{array}$ & $\begin{array}{l} \pm 3 \\
\pm 1 \\
\pm 1\end{array}$ & \\
\hline $\begin{array}{l}\text { Insert Plug } \\
\text { Interval }\end{array}$ & $\begin{array}{l}\text { Between edges and insert plug } \\
\text { space of vertical direction space of } \\
\text { horizontal direction }\end{array}$ & $\begin{array}{l}\text { Scale } \\
\text { Scale / Gauge } \\
\text { Scale / Gauge }\end{array}$ & $\begin{array}{l}255 \\
565 \\
280 \\
\end{array}$ & $\begin{array}{l} \pm 0.5 \\
\pm 0.5 \\
\pm 0.5\end{array}$ & $\begin{array}{l} \pm 1 \\
\pm 1 \\
\pm 1\end{array}$ & \\
\hline Insert Position & $\begin{array}{l}\text { Edge side and insert interval } \\
\text { Insert Space }\end{array}$ & $\begin{array}{l}\text { Scale } \\
\text { Scale }\end{array}$ & $\begin{array}{l}820 \\
120\end{array}$ & $\begin{array}{l}\text { Person } 1.5 \\
\pm 1.5\end{array}$ & $\begin{array}{l} \pm 3 \\
\pm 3\end{array}$ & \\
\hline Planarity & The horizontal degree twist & Level/Scale & $\begin{array}{r}1 / 10 \\
\text { Visual } \\
\text { Inspections }\end{array}$ & \pm 0.5 & \pm 1 & \\
\hline Projection Part & Size and position of Radius & Gauge & 300 & \pm 1.5 & \pm 3 & \\
\hline Wart & Warp of Center Rail & Gauge/String & & \pm 1.5 & \pm 3 & \\
\hline Inside Form & $\begin{array}{l}\text { Position of direction of length } \\
\text { Horizontal position } \\
\text { Inside measurement in direction of } \\
\text { length (outside) } \\
\text { Inside measurement in direction of } \\
\text { length (inside) } \\
\text { Inside measurement in direction of } \\
\text { width (outside) } \\
\text { Inside measurement in direction of } \\
\text { width (inside) }\end{array}$ & $\begin{array}{l}\text { Scale } \\
\text { Scale } \\
\text { Steel Tape } \\
\text { Steel Tape } \\
\text { Steel Tape } \\
\text { Steel Tape }\end{array}$ & $\begin{array}{r}1,020 \\
710 \\
1,860 \\
1,660 \\
800 \\
600 \\
\end{array}$ & $\begin{array}{l} \pm 1.5 \\
\pm 1.5 \\
\pm 1.5 \\
\pm 1.5 \\
\pm 1.5 \\
\pm 1.5 \\
\end{array}$ & $\begin{array}{l} \pm 3 \\
\pm 3 \\
\pm 3 \\
\pm 3 \\
\pm 3 \\
\pm 3\end{array}$ & \\
\hline
\end{tabular}

(Source of data: "T220 inspection and test proposal" by THSR) 


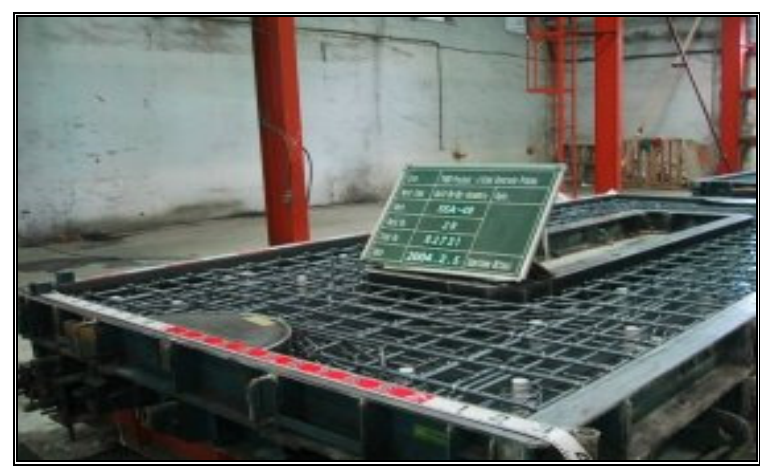

Figure 6. Inspection of reinforcement

\subsubsection{Concrete inspection}

For any disqualification of slump, chlorine ion content, air content and concrete temperature under inspection, the material is rejected and not allowed to be used.

Obtain 9 specimens for every placing, cure 6 of them together with the slab track (after steam curing, place them in the curing pool for 3 days) and the remaining 3 specimens are cured by means of the general standard.

Test the specimens cured together with the slab track for strength after formwork removal and 7 days. For specimens cured by means of general standard, apply the 28-day compressive strength test.

If the concrete strength does not reach $30 \mathrm{Mpa}$, curing must be continued until qualified according to testing the strength.

Results of all compressive crushing are recorded and an X-R chart is produced to control the concrete quality.

\subsubsection{Steam curing}

The curing starts 3 hours after concrete placing.

The rate of temperature increase and decrease shall not exceed $15^{\circ} \mathrm{C} /$ hour.

The maximum temperature must be $50 \sim 60^{\circ} \mathrm{C}$ and the duration shall not exceed 6 hours.

The temperature shall be controlled and recorded automatically.

The steam outlet shall not aim at the steel mold.

\subsubsection{Product inspection}

All results are displayed in numbers and recorded on the check form (Figure 7).

Visually inspect the product appearance first. If repair or correction of defect is required, it shall be approved by the QC personnel first.

Measure the length and width of the slab track with stainless ruler at inspection frequency per unit.

Measure the thickness of slab track with vernier caliper at inspection frequency per unit.

Measure the levelness of slab surface with special instrument at inspection frequency per unit.

Use square and nylon string to check surface curvature and center line of the track at inspection frequency per unit.

Use special steel gauge to measure spacing and curvature of embeds at inspection frequency per unit.

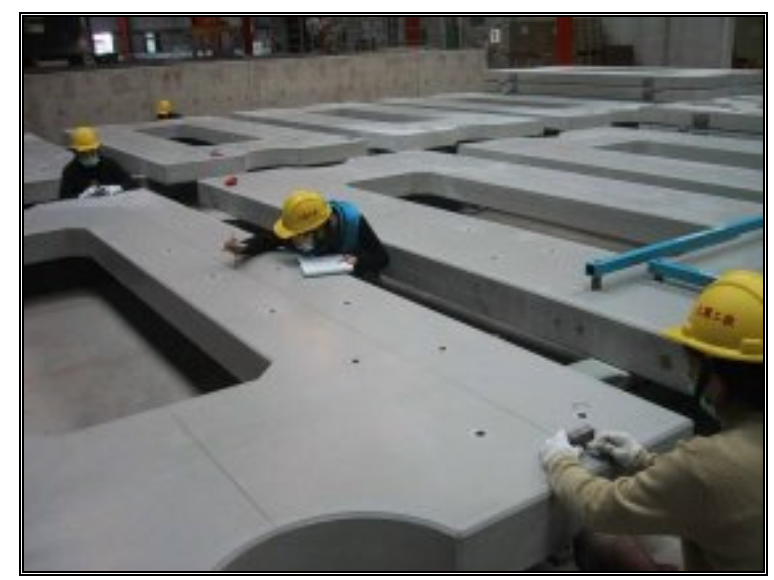

Figure 7. Products check of slab tracks

\subsubsection{Other note items}

The making of product marks includes manufacturing date, slab number, check number and protective coating (Figure 8).

After completion of all checking and repairing, place the slab tracks in curing pools with water for 3 days (Figure 9). 


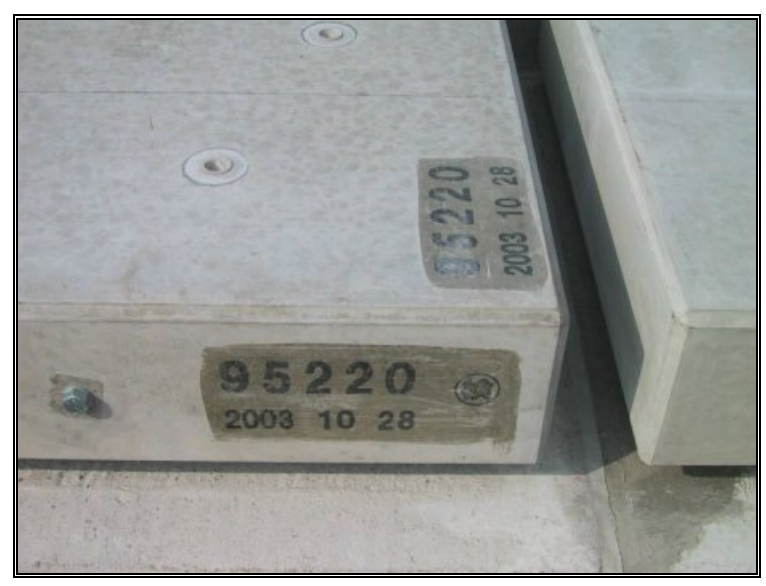

Figure 8. Making product marks

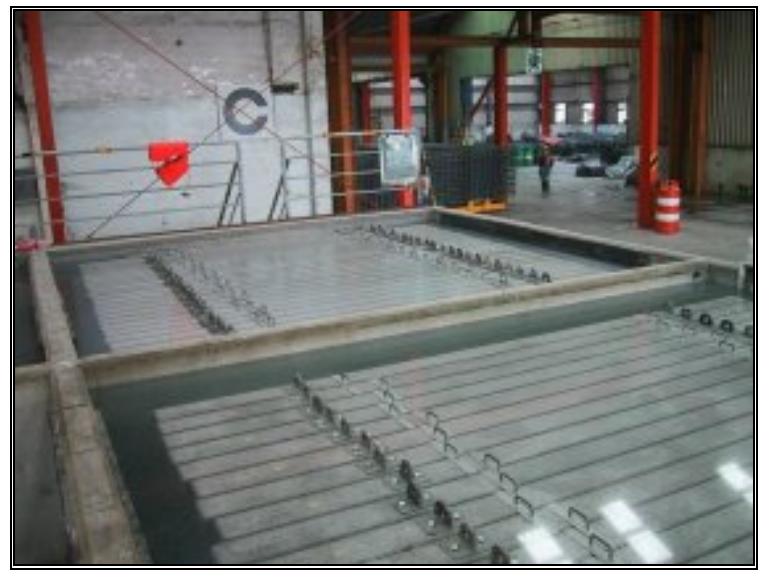

Figure 9. Curing of slab tracks in water

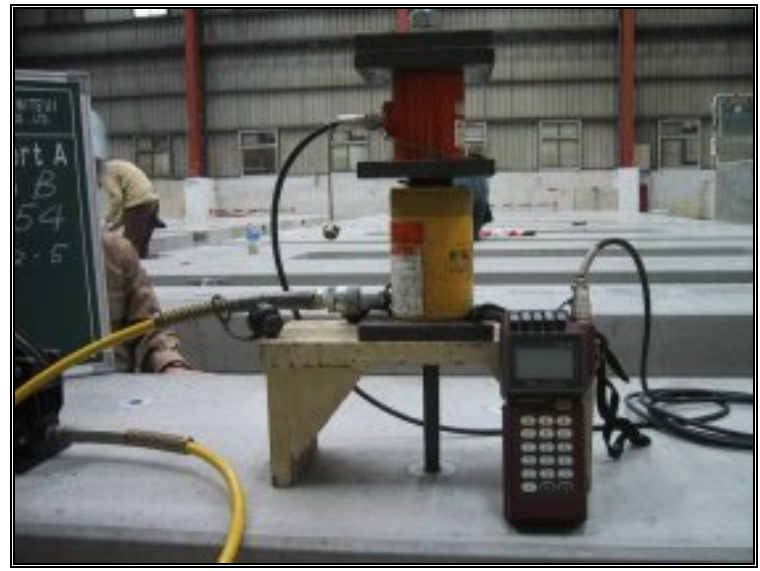

Figure 10. Pulling test on insert plug A and C
Inspection and testing of ground resistance must be carried out before and after concrete placing. The ground resistance shall be less than $0.2 \Omega$.

Perform one pulling test on insert plug $\mathrm{A}$ and $\mathrm{C}$ for production of every 500 slab tracks (Figure 10) with test load of $49 \mathrm{KN}$.

\section{INVENTORY MANAGEMENT}

\subsection{Storage of slab tracks}

Compact and roll the ground of piling field to the required density and pave gravel onto the ground, as well as placing the slide under the slab tracks (Figure 11).

Place according to direction shown in drawing.

Fix slabs onto the steel frames with metal connector and screws to prevent toppling.

Fix 4 rubber pads on the slab surface to prevent collision between slabs.

Seal the insert holes on the slab track with tape or plastic cover to prevent stacking of dusts.

Record storage of slab tracks in detail, follow up and renew the records every day to see the date of production for slab track at each position.

\subsection{Delivery checking}

The schedule and amount of slab track delivery will be notified by TST JV in official letter.

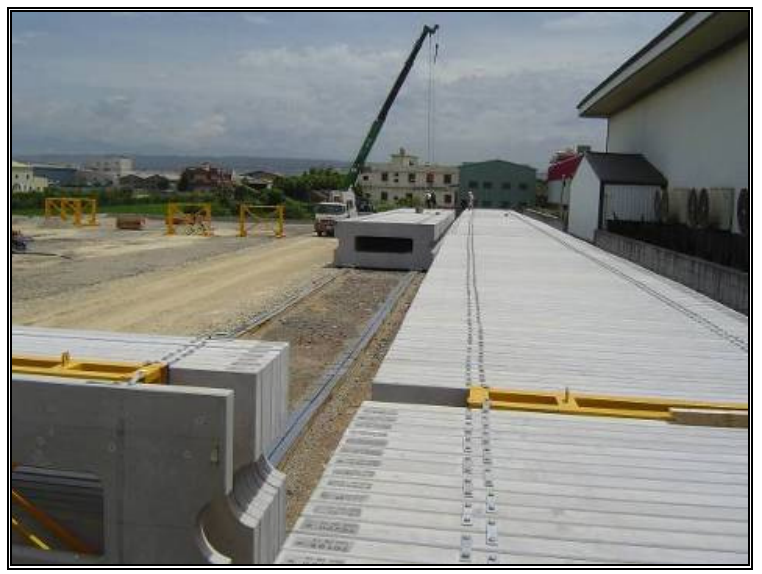

Figure 11. Slab storage area 
Before delivery, the appearance, numbering, quantity and transportation arrangement of the products will be visually checked again.

The results of check before delivery will be recorded on the check form daily.

\section{CONCLUSIONS AND SUGGESTIONS}

The value of the brand is a goal that is pursued by contemporary enterprises. "Japanese Shinkansen" spent 40 years of operation performance and safety guarantees to build an irreplaceable brand. The final value of a brand image is to establish customer loyalty that drives customers to trust a certain product at a higher price. For achievements in this aspect, the Japanese enterprises obviously stand at the leading position worldwide.

The pre-cast cement product is a specified good that is produced in a factory and free from natural factors such as weather and environment. As long as the planning is adequate with good operation, such product is rather easy to manage and control in the construction field. In view of the current construction environment in Taiwan, regretfully, our quality system is still at the inspection stage; the request on product takes compliance with contract or regulation as condition of satisfaction and there is lack of motivation for self-improvement. The product of HSR slab tracks demonstrate a perfect surface and extremely high precision of dimension that is almost as fine as metal products, which is not the achievement from checking at the end of the production line. The habit of the Japanese industry with thorough systemization, documentation, standardization, and hands-on principles for process of management actually cover many contents, which are worthwhile and our cement plants have been recommended to learn from.

\subsection{Focus on planning thorough participation}

The basic guideline for quality management now is that "Quality is derived from good planning and design instead of good checking". The essence of quality management focuses on planning since "one can only perform the work right with good preparation in advance". The "preparation" refers not only to the tools and equipment, but also a way of planning since certain materials or equipment can only achieve a boosted effect with development in ad- vance. For the mold developed for production of slab tracks, the assembly is fast, easy and safe; after testing, the stability and precision can still be maintained with excellent functions after vibration. For vibration control during concrete placing, the JV adopts fully automatic vibrating system with external mold, which automatically adjusts to different vibration frequencies according to different times, so the concrete can reach an optimal state. With development of special measurement, checking on tools and equipment, as well as continuous testing, a great amount of energy is required at the stage of initial planning, so high level quality of the product can be acquired.

After delivery of slab tracks, the surface damage generated from collision during site installation or transportation must be repaired by professional personnel from the manufacturer. TST JV has drafted a set of repair plans (Figure $12 \& 13$ ); in addition to the requirement that product strength and durability after repair shall not be less than the requirement of the original quality; the appearance is almost the same as the original surface. This has verified that "thorough quality management is the management on all processes". From planning to "after-sales service", not a single stage is allowed to be out of the managing scope.

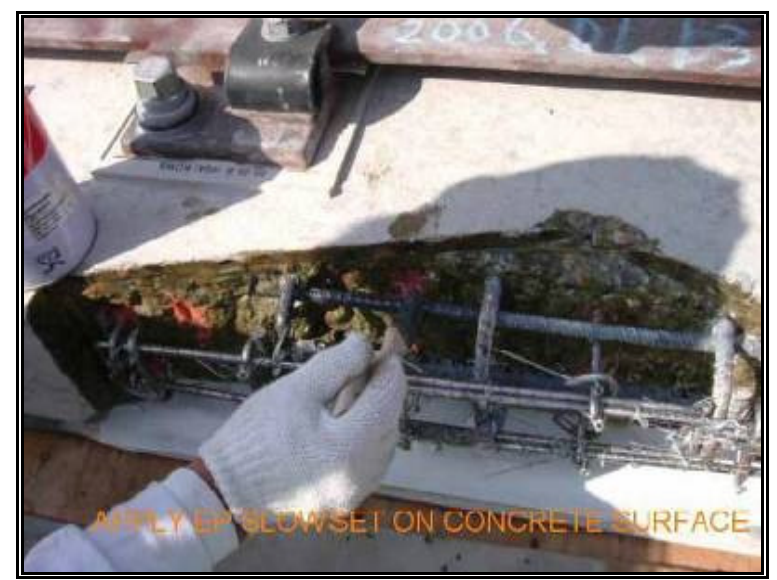

Figure 12. Reinforce and surface bonding layer 


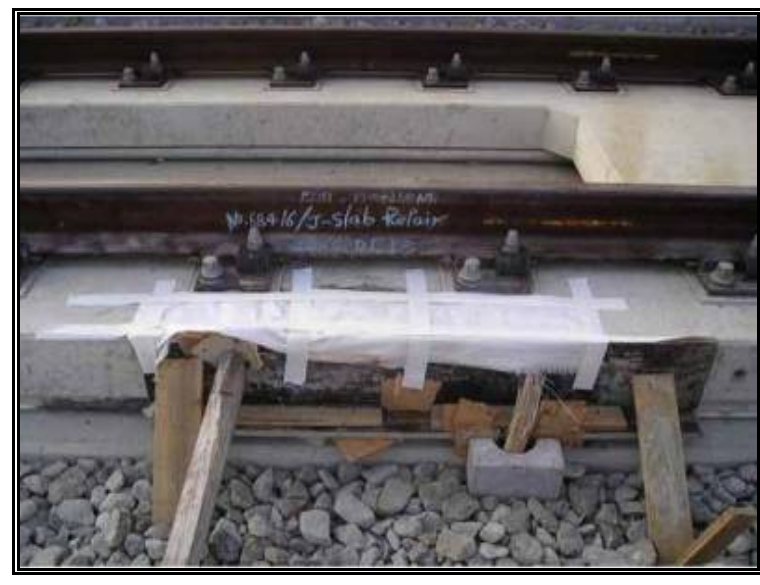

Figure 13. Chemical curing

\subsection{Execution according to written document}

The significance of establishing the managing structure of ISO9001 Quality documentation system is to execute according to procedures, steps and methods contained in the documents instead of demonstrating the amount of execution. Rich content of documents does not represent good performance since too many enterprises (including official departments) in Taiwan only correspond to the requirement by using many forms without practice execution. The documents are often supplemented upon audit and the auditor even cooperates with such situation, which leads the whole process to be merely show.

With detail documents in the factory, the details, steps and inspections of each work is recorded clearly. When an error occurs in any process, the cause can be traced right away. The records can even trace back to the very shift, date, assembly platform of reinforcement cage, as well as the mold set placed and batch number of reinforcement used. Any cause of disqualification can be traced, reviewed and further improved. Such mindset of high self discipline in quality control that is executed in accordance with written documents sets the foundation for excellent quality.

\subsection{Look at the bigger picture and performing from the details}

The quality is improved by looking at the bigger picture and performing from the details. The work from places that are neglected needs the concept of all- position quality operation. The spacer that controls the protective layer has never received attention; yet in order to achieve consistency of product appearance and material, the JV has specifically customized two styles for the spacer, which are made with high strength $(>40 \mathrm{Mpa})$ cement mortar (Figure 14). The exposed elevation applies $V$ shape to reduce the area of exposure and color difference. The spring clips attached are used for easy fixture of the spacer onto the reinforcement, which do not fall and displace easily; furthermore, drawings are used to specify the tolerance together with the style and position of installation.

In order to achieve the perfect surface of a product, steel plates are used to extract residual bubbles on the surface after completion of concrete placing and vibration of external mold (Figure 15). During the stage of checking product surface, bubbled holes larger than $3 \mathrm{~mm}$ are requested to be leveled out; hence bubbled holes or defects are hardly seen from the product surface.

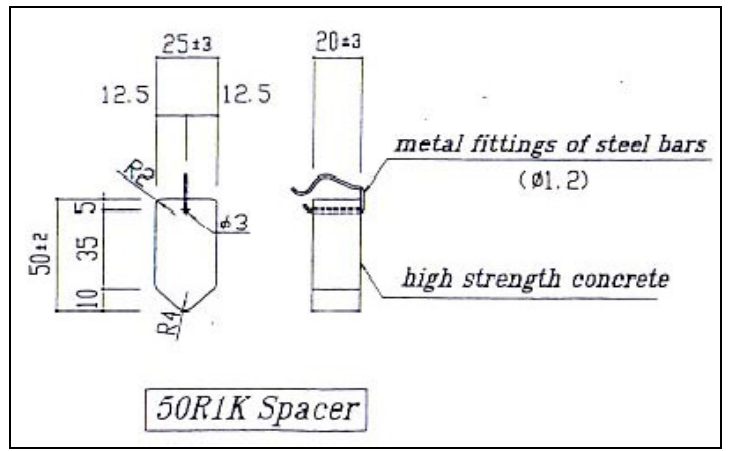

Figure 14. Spacer

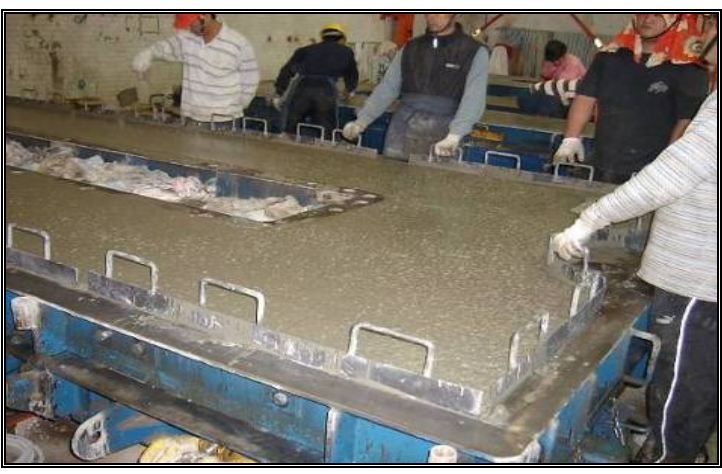

Figure 15. Steel plates used to extract bubbles 


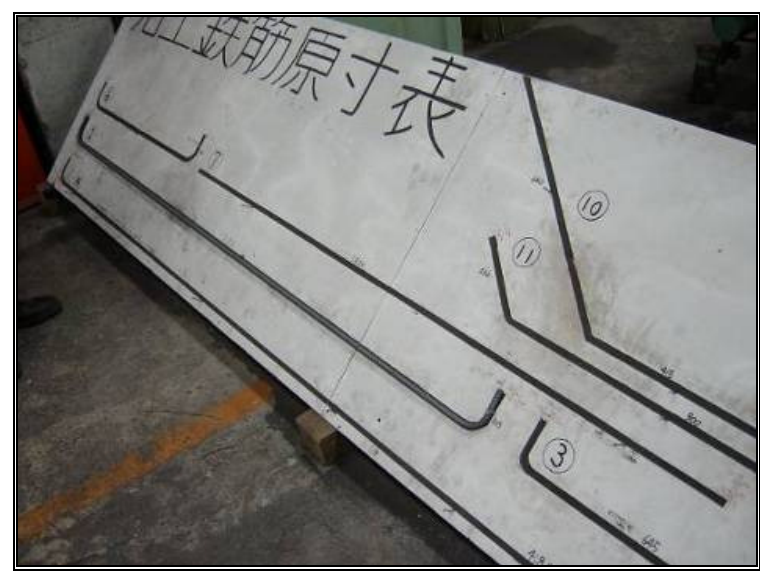

Figure 16. Full-scale reinforcement tolerance sample for calibration

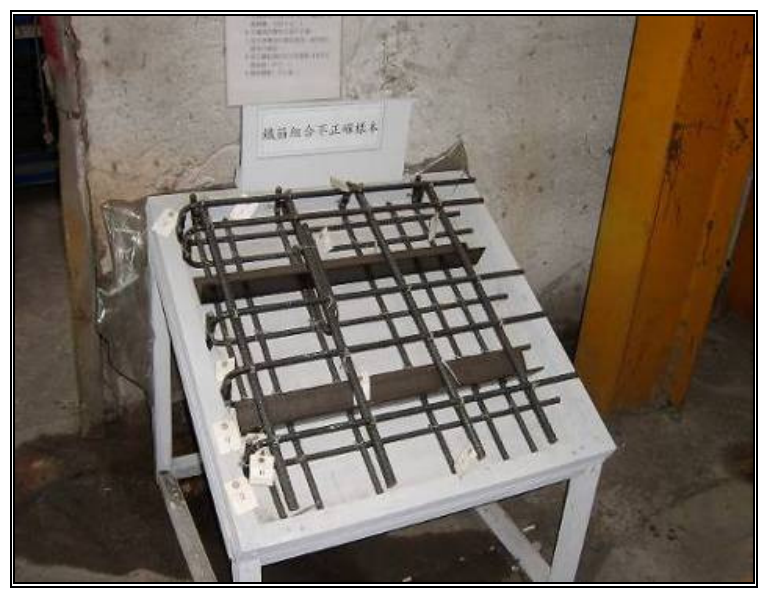

Figure 17. Model of tying reinforcement

\subsection{Well use of minor techniques}

Well use of many minor assistances or techniques for the sake of product requirement is also one of the features in quality management made by the factory. For example, they use full-scale reinforcement samples (Figure 16) and label the tolerance, so workers are requested to perform and calibrate reinforcement of each dimension at a frequency of one calibration per 300 bars.

By making the fine center line of track engraved on the mold, deformation of mold can be detected immediately if any inconsistency is found during product test. The use of model for tying reinforcement
(Figure 17) demonstrates the category of easy mistakes with actual examples and descriptions, which achieves a magnified effect of educating personnel expertise. In fact, good use of minor techniques does not induce excessive costs to the enterprise, but the results are often obvious and effective.

\subsection{Putting training into practice}

The purpose of putting training into practice is to allow absorption of new knowledge and experience by the personnel, which can be converted into motivation of work improvement. The sense of belonging towards the enterprise can also be consolidated together with cheering up the spirit of personnel, which achieves the goal of improving operation efficiency and incubation of talented personnel. The training offered by JV to its personnel is divided into (1) Tool box talking: Hazard notification and work reminder prior to daily commencement; (2) Training of new personnel: Basic training of new personnel under legal regulations; (3) Professional training: Training of occupational skills; (4) Regular training: Training with time request or return; and (5) Special training: Training for special personnel or technique; for example, the repair personnel of slab track can only enter the work area for repair after receiving the HSR's unique TCOMP (Test, Commissioning, Operation and Maintenance Procedures) training.

\section{REFERENCES}

[1] Kai-Tao Chen, ( June 2002) "Dynamic analysis of slab tracks", Master thesis for Institute of Civil Engineering and Disaster Prevention, National Taipei University of Technology.

[2] Chu-An Chen and Ran Huang, "Evaluation and comparative study on performance efficiency of ballastless track for Taiwan Railways", Presentation seminar of 2002 Master class, Department of Harbor and River Engineering, National Taiwan Ocean University.

[3] http://www.thsrc.com.tw/main/construct/track/ 05.asp.

[4] Compiled work information (2004 2005), THSR. 
[5] Chin-Nan Cheng, (24th March 2004) "Light discussion on QA/AC of HSR civil works", Engineering gazette.

[6] Bureau of High Speed Rail, MOTC, (December 2006) "General description on construction of HSR track works".

[7] THSR, (October 2003) "T220 inspection and test proposal". 